\title{
Relação entre consumo alimentar da população nordestina e o alto índice de câncer gástrico nesta região
}

\author{
Victor Alves de Oliveira
}

\begin{abstract}
Núcleo de Pesquisa em Biotecnologia Aplicada a Saúde e Meio Ambiente - NUPBSAM

Aluno do Curso de Nutrição do Campus Senador Helvídio Nunes de Barros - Universidade Federal do Piauí. CSHNB.
\end{abstract}

\section{Thayse Wilma Nogueira de Oliveira}

Núcleo de Pesquisa em Biotecnologia Aplicada a Saúde e Meio Ambiente - NUPBSAM

Aluna do Curso de Nutrição do Campus Senador Helvídio Nunes de Barros - Universidade Federal do Piauí. CSHNB.

\section{Marcus Vinicius Oliveira Barros de Alencar}

Laboratório de Pesquisa em Genética Toxicológica

Aluno da Pós Graduação em Ciências Farmacêuticas Universidade Federal do Piauí. CSHNB.

\section{Gilberto Santos Cerqueira}

Laboratório de Anatomia Universidade Federal do Piauí, CSHNB

Doutor do Curso de Nutrição do Campus Senador Helvídio Nunes de Barros - Universidade Federal do Piauí. CSHNB.

\section{Ana Paula Peron}

Núcleo de Pesquisa em Biotecnologia Aplicada a Saúde e Meio Ambiente - NUPBSAM

Professora Doutora do Curso de Ciências Biológicas do Campus Senador Helvídio Nunes de Barros - Universidade Federal do Piauí. CSHNB.

OLIVEIRA, Victor Alves de; OLIVEIRA, Thayse Wilma Nogueira de; ALENCAR, Marcus Vinicius Oliveira Barros de; PERON, Ana Paula; SOUSA, João Marcelo de Castro e. Relação entre consumo alimentar da população nordestina e o alto índice de câncer gástrico nesta região. RevInter Revista Intertox de Toxicologia, Risco Ambiental e Sociedade, v. 7, n. 3, p. 06-24, out. 2014. 


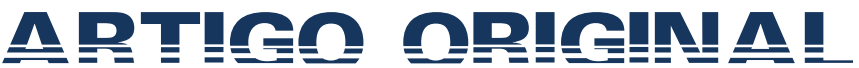

\section{João Marcelo de Castro e Sousa*}

Núcleo de Pesquisa em Biotecnologia Aplicada a Saúde e Meio Ambiente - NUPBSAM

Professor Mestre do Curso de Ciências Biológicas do Campus Senador Helvídio Nunes de Barros - Universidade Federal do Piauí. CSHNB.

*Autor para correspondência: João Marcelo de Castro e Sousa, e-mail: j.marcelo@ufpi.edu.br,fone (86) 81006336.

\section{RESUMO}

No mundo, o câncer de estômago figura como a segunda maior causa de morte por câncer. A relação entre câncer gástrico e nutrição é apontada em vários estudos, sendo a dieta um fator exógeno bastante relevante. Dessa forma, este trabalho teve como objetivo cruzar dados do perfil alimentar da população do nordeste brasileiro com estudos que investigaram a relação entre as neoplasias gástricas e os principais alimentos consumidos, para explicar a alta incidência desta neoplasia na região. Para isso, foi realizada uma revisão de literatura, por meio de buscas bibliográficas nos bancos de dados informatizados Medline/Pubmed, Scielo e Lilacs, no período de maio a julho de 2013, considerando artigos que investigaram a relação entre neoplasias gástricas e a alimentação. Foram encontrados 43 artigos, dos quais 21 atenderam aos critérios de inclusão do estudo, e estes foram divididos em dois grupos. O primeiro com as características alimentares do nordeste, e o segundo, a influência dos alimentos tradicionais nas neoplasias gástricas. Analisando os artigos: arroz, café, feijão, carne e refrigerantes estão entre os principais alimentos consumidos pela população nordestina e alguns desses alimentos possuem, na sua composição ou na sua conservação, substâncias carcinogênicas. Observou-se também que alguns alimentos, ditos preventivos para tal patologia, são os menos consumidos pela população dessa região. Portanto, pode-se notar que a alimentação da população nordestina parece possui uma estreita relação com o desenvolvimento e a alta incidência do câncer gástrico, sendo um fator de risco a ser considerado e estudado para a redução dessa patologia na região.

Palavras-chaves: Câncer gástrico. Alimentação. Nordeste. Brasil.

OLIVEIRA, Victor Alves de; OLIVEIRA, Thayse Wilma Nogueira de; ALENCAR, Marcus Vinicius Oliveira Barros de; PERON, Ana Paula; SOUSA, João Marcelo de Castro e. Relação entre consumo alimentar da população nordestina e o alto índice de câncer gástrico nesta região. RevInter Revista Intertox de Toxicologia, Risco Ambiental e Sociedade, v. 7, n. 3, p. 06-24, out. 2014. 


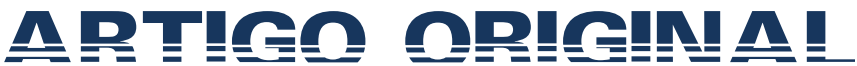

\section{ABSTRACT}

Worldwide, stomach cancer appears as the second leading cause of cancer death. The relationship between gastric cancer and nutrition is suggested in several studies, the diet being a very important exogenous factor. Thus, this paper aims to cross data between dietary profile of the northeastern Brazilian population with studies that investigated the relationship between gastric cancer and the main food items consumed, to explain the high incidence of this tumor in the region. For this, a literature review, through literature searches in computerized databases Medline / Pubmed, Lilacs and SciELO, from the period May to July 2013, considering articles that investigated the relationship between gastric cancer and diet. Overall 43 papers were found, of which 21 met the inclusion criteria. The included papers were divided into two groups. The first with northeast region dietary characteristics, and the second, with the influence of traditional food on gastric neoplasms. The items: rice, coffee, beans, meat and soft drinks are among the main food item consumed by the population and some of these foods have in their composition or their storage process, carcinogenic substances. It was also observed that the population of that region consumes less preventive food items for such pathology. Therefore, it can be noted that the diet of the Northeastern population has a close relationship with the development and high incidence of gastric cancer. Such a risk factor must be considered and studied to reduce this pathology in this region

Keywords: Gastric Cancer. Food. Northeast. Brazil.

OLIVEIRA, Victor Alves de; OLIVEIRA, Thayse Wilma Nogueira de; ALENCAR, Marcus Vinicius Oliveira Barros de; PERON, Ana Paula; SOUSA, João Marcelo de Castro e. Relação entre consumo alimentar da população nordestina e o alto índice de câncer gástrico nesta região. RevInter Revista Intertox de Toxicologia, Risco Ambiental e Sociedade, v. 7, n. 3, p. 06-24, out. 2014. 


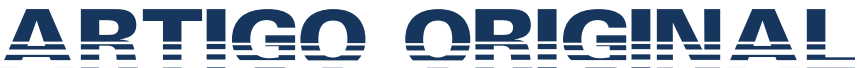

\section{INTRODUÇÃO}

No mundo, um dos tipos mais comuns de câncer é o de estômago e este figura como a segunda maior causa de morte por câncer. A mais recente estimativa mundial apontou a ocorrência de cerca de um milhão de casos novos de câncer de estômago para o ano de 2014, configurando-se como a quarta causa mais comum de câncer. Mais de 70\% dos casos ocorreram em países em desenvolvimento, como o Brasil. E, além disso, a incidência é cerca de duas vezes mais alta no sexo masculino do que no feminino. Para o ano de 2014, estima-se, para o Brasil, 20.390 novos casos, sendo 12.870 homens e 7.520 mulheres. Para a região Nordeste, foco do estudo, sem considerar os tumores de pele não melanoma, o câncer de estomago é o segundo em homens (9/100 mil) e o sexto mais frequente entre as mulheres (6/100 mil) (INCA 2014).

O câncer gástrico é uma patologia de etiologia multifatorial, em que os tumores se desenvolvem a partir de lesões na mucosa gástrica, ocasionadas pela ação e/ou interação de fatores de risco, ou seja, é um processo que inclui várias etapas sendo resultado da exposição a fatores endógenos (genéticos) e exógenos (ambientais), por um longo período de tempo (CARVALHO et al. 2010).

Para os fatores endógenos, as alterações no material genético se destacam no desenvolvimento e progressão do câncer gástrico, tendo alterações em oncogenes e genes supressores de tumores (genes que controlam o ciclo celular) assim como em outros mecanismos de controle da estabilidade genômica, respondendo pelo aparecimento dessa patologia. As alterações descritas até agora incluem amplificações e mutações nos seguintes genes: c-ERBB2, KRAS, MET, TP53 e c-MYC (RIBEIRO et al. 2010).

A relação entre câncer gástrico e nutrição é apontada em vários estudos, sendo a dieta um fator exógeno bastante relevante. Entre os fatores

OLIVEIRA, Victor Alves de; OLIVEIRA, Thayse Wilma Nogueira de; ALENCAR, Marcus Vinicius Oliveira Barros de; PERON, Ana Paula; SOUSA, João Marcelo de Castro e. Relação entre consumo alimentar da população nordestina e o alto índice de câncer gástrico nesta região. RevInter Revista Intertox de Toxicologia, Risco Ambiental e Sociedade, v. 7, n. 3 , p. 06-24, out. 2014. 


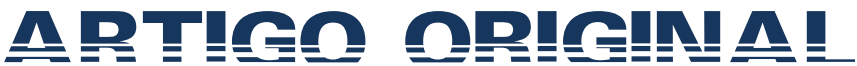

dietéticos associados à carcinogênese gástrica, vale ressaltar que dietas com altas concentrações de cloreto de sódio, nitrito e nitrato, presentes em alimentos defumados e frituras, são o ponto inicial para provocar transformações na mucosa gástrica, podendo dar início a esta neoplasia (MELO et al. 2012). Acredita-se que cerca de 35\% dos diversos tipos de câncer ocorrem em razão de dietas inadequadas. É possível identificar, por meio de estudos epidemiológicos, associações relevantes entre alguns padrões alimentares observados em diferentes regiões do globo e a prevalência de tal patologia (GARÓFOLO et al. 2004).

Características regionais apontadas no consumo individual confirmam os perfis diferenciados de disponibilidade de alimentos que caracterizam as cinco grandes regiões do Brasil. O rendimento familiar é importante para caracterizar a disponibilidade domiciliar de alimentos e o consumo individual. O aumento da presença de frutas, verduras, legumes e do refrigerante esta ligado a um maior rendimento familiar, e a tendência inversa também foi observada para o consumo de feijão e farinha de mandioca (JAROSZ et al. 2012).

Diversos autores apontam estudos que mostram a dieta habitual como importante fator no aparecimento do câncer de estômago. Entre os fatores de risco para essa neoplasia, está uma dieta rica em gorduras animais e com baixa ingestão de frutas, vegetais e cereais. Além da dieta inadequada, estão entre os fatores de risco o alcoolismo, sedentarismo e a infecção alimentar pela Helicobacter pylori.

Diante do exposto, o objetivo do estudo foi cruzar dados de perfil alimentar da população do nordeste do Brasil com estudos que investigaram a relação entre as neoplasias gástricas e os principais alimentos consumidos por esta população, sejam eles carcinogênicos ou anticarcinogênicos, explicando assim a alta incidência desta neoplasia na região.

OLIVEIRA, Victor Alves de; OLIVEIRA, Thayse Wilma Nogueira de; ALENCAR, Marcus Vinicius Oliveira Barros de; PERON, Ana Paula; SOUSA, João Marcelo de Castro e. Relação entre consumo alimentar da população nordestina e o alto índice de câncer gástrico nesta região. RevInter Revista Intertox de Toxicologia, Risco Ambiental e Sociedade, v. 7, n. 3, p. 06-24, out. 2014. 


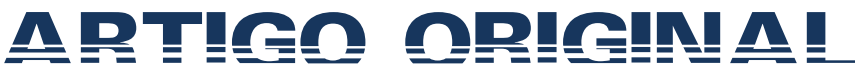

\section{METODOLOGIA}

Foi realizada uma revisão de literatura, por meio de buscas bibliográficas nos bancos de dados informatizados Medline/Pubmed, Scielo e Lilacs, no período de maio a julho de 2013. Considerou-se os artigos que investigaram a relação entre neoplasias gástricas e a alimentação, incluindo uma pesquisa das características alimentares do nordeste do Brasil. Incluíram-se artigos de estudos epidemiológicos transversais, ecológicos, revisão, caso-controle e coorte publicados no período de 2008 a 2013. Não foram inseridos no estudo, artigos nos quais o câncer foi investigado em relação a suas consequências para o estado nutricional. Excluíram-se também, aqueles que não estavam disponíveis na íntegra, visto que esse fato dificultava e/ou impossibilitava a extração de informações relevantes para a investigação dos fatores e desfecho analisados.

As buscas foram conduzidas por meio do formulário avançado utilizando no campo "descritores de assunto" as seguintes palavras-chave em português e seus correspondentes em inglês: neoplasias gástricas, fatores de risco, consumo alimentar, alimentos, câncer de estômago e características alimentares do nordeste do Brasil. Todas as palavras-chave constam nos descritores em ciências da saúde.

Do conjunto de artigos identificados, foram selecionados os relacionados com os hábitos alimentares, e estudos que comprovem a interação dos principais alimentos consumidos na região com 0 aparecimento destas neoplasias.

\section{RESULTADOS E DISCUSSÃO}

Foram encontrados 43 artigos, dos quais 21 atenderam aos critérios de inclusão do estudo, compreendendo artigos de revisão, caso controle, epidemiológicos e transversais.

OLIVEIRA, Victor Alves de; OLIVEIRA, Thayse Wilma Nogueira de; ALENCAR, Marcus Vinicius Oliveira Barros de; PERON, Ana Paula; SOUSA, João Marcelo de Castro e. Relação entre consumo alimentar da população nordestina e o alto índice de câncer gástrico nesta região. RevInter Revista Intertox de Toxicologia, Risco Ambiental e Sociedade, v. 7, n. 3, p. 06-24, out. 2014. 


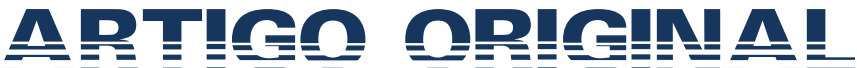

Os artigos foram divididos em dois grupos. O primeiro continha aqueles que tratavam das características alimentares do nordeste, e o segundo, os que citavam a influência de cada um dos alimentos mais consumidos na região com o aparecimento de neoplasias gástricas. A partir dos artigos base do grupo um, foi feito um cruzamento de dados para traçar o perfil alimentar da população do nordeste do Brasil.

Com a pesquisa foi possível traçar o perfil alimentar do nordestino, que mostrou que os alimentos mais consumidos pela população da região de um modo geral são: arroz (84\%), café (79\%), feijão (72,8\%), pão de sal (63\%) e carne bovina (48,7\%). A banana foi a fruta mais citada $(16,0 \%)$ e a salada crua (16\%) a preparação incluindo verduras mais frequentes entre os brasileiros. A prevalência do consumo de sucos e refrescos foi de $39,8 \%$ e de refrigerantes $23 \%$, assim estes ocuparam, respectivamente, a sexta e nona posições entre os alimentos mais consumidos. A prevalência de consumo do leite integral foi de $12,4 \%$ e a de queijos, $13,5 \%$. Biscoito salgado (15,9\%), bolos $(13,4 \%)$, e doces $(11,7 \%)$ também estiveram entre os 20 alimentos com maior prevalência de consumo no País.

Entre os trabalhos analisados, o de Souza e colaboradores (2013) mereceu destaque pois construíram em sua pesquisa o ranking dos 20 alimentos mais consumidos no Brasil, a partir do Inquérito Nacional de Alimentação, onde são levados em consideração fatores regionais, econômicos e sociais para o consumo alimentar. $\mathrm{O}$ café foi o item de maior prevalência no Nordeste (83,6\%). Sucos e refrescos também figuraram entre os itens de maior consumo ficando em sexta posição no ranking. A prevalência do consumo de refrigerantes foi de $16,1 \%$, o que corresponde à $14^{\mathrm{a}}$ posição. Hortaliças foram mais frequentemente citadas sob a forma de salada crua no Nordeste ( $20^{\mathrm{a}}$ posição, $\left.10,6 \%\right)$.

Alguns itens, que aparecem entre os mais prevalentes somente em algumas regiões, marcam características locais no consumo de alimentos, por exemplo, a farinha de mandioca na região Nordeste ( $13^{\text {a }}$ posição, $\left.18,2 \%\right)$. Os

OLIVEIRA, Victor Alves de; OLIVEIRA, Thayse Wilma Nogueira de; ALENCAR, Marcus Vinicius Oliveira Barros de; PERON, Ana Paula; SOUSA, João Marcelo de Castro e. Relação entre consumo alimentar da população nordestina e o alto índice de câncer gástrico nesta região. RevInter Revista Intertox de Toxicologia, Risco Ambiental e Sociedade, v. 7, n. 3 , p. 06-24, out. 2014. 


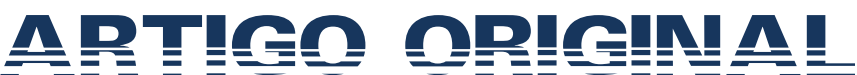

doces também aparecem entre os itens mais consumidos na região, com prevalência em torno de 13\%. Já os salgados fritos e assados não figuraram entre estes itens. Os biscoitos salgados e os ovos estão entre os mais prevalentes em todas as regiões do país, e os peixes também foram citados com importância no Nordeste.

A partir do estudo de Souza e colaboradores (2013) foi analisado alimentos com alta incidência para região Nordeste e que ao mesmo tempo possuem na sua constituição compostos que são fatores de risco para o desenvolvimento e progressão do processo de carcinogênese gástrica. Como também foram avaliados e analisados alimentos de baixa incidência na mesma região do País e que possuem propriedades antineoplásicas.

\section{Alimentação como fator de risco para o câncer gástrico na Região Nordeste}

\section{Café}

Dentre todos os alimentos citados no consumo diário dos nordestinos o café obteve o maior destaque ocupando o topo do ranking de consumo. O café é uma das matérias-primas com maior importância no comércio internacional. É igualmente uma das bebidas mais apreciadas em todo mundo, não só pelas suas características organolépticas, mas também pelo seu efeito estimulante (ALVES et al. 2009).

Esta é uma bebida muito consumida pela população, que possui uma mistura complexa de diferentes moléculas com atividade genotóxica, como o metilglioxal, o peróxido de oxigênio e os dicarbonos alifáticos, formados durante o processo de torrefação. Düsman et al. (2012) mostram que o café induz mutações em várias cepas de Salmonella typhimurium, em células de hamster Chinês e em linfócitos humanos. O café instantâneo também possui atividade genotóxica, tanto por seus constituintes como pela formação dos compostos fenólicos decorrentes da auto-oxidação do mesmo.

OLIVEIRA, Victor Alves de; OLIVEIRA, Thayse Wilma Nogueira de; ALENCAR, Marcus Vinicius Oliveira Barros de; PERON, Ana Paula; SOUSA, João Marcelo de Castro e. Relação entre consumo alimentar da população nordestina e o alto índice de câncer gástrico nesta região. RevInter Revista Intertox de Toxicologia, Risco Ambiental e Sociedade, v. 7, n. 3, p. 06-24, out. 2014. 


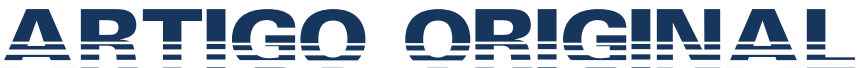

Estudos realizados demonstraram que a cafeína, presente em chás e cafés, afeta a ação reparadora do DNA durante a divisão celular, modifica a resposta apoptótica e altera o funcionamento do gene p53, que codifica uma proteína reguladora do ciclo celular. Além disso, o café e a cafeína são capazes de interagir com muitos outros mutagênicos e os seus efeitos são sinergísticos junto com raios-X, luz ultravioleta e alguns agentes químicos (DÜSMAN et al. 2012).

\section{Carne}

A carne bovina também é um alimento muito consumido na região nordeste, figurando entre os cinco itens mais consumidos (JAROSZ et al. 2012). O Departamento de Saúde dos Estados Unidos considera que existe uma associação de risco moderado consistente entre o consumo de carnes processadas e o câncer do trato gastrointestinal (MAGALHÃES et al. 2008).

Está bem documentado na literatura que os compostos N-nitrosos e o nitrato induzem à formação tumoral por meio da sua transformação em nitrito, um óxido desestabilizado, que pode acarretar danos ao material genético, causando assim uma lesão celular. O nitrito, que pode ser formado endogenamente, também provém das carnes curadas (conservadas com nitrito de sódio), embutidos e alguns vegetais (espinafre, batata, beterraba, alface, tomate, cenoura, nabo, couve-flor, repolho, rabanete, etc.) que contêm nitrato, o qual é transformado em nitrito pela ação da saliva. Os mecanismos postulados para o aumento do risco do câncer de estômago com o consumo de compostos nitrosos estão associados ao aumento de radicais livres, que promovem lesão celular com redução na produção de muco, um fator de proteção à mucosa gástrica (MAGALHÃES et al. 2008).

Métodos de preservação e preparo de carnes, que acarretam a formação de amina heterocíclicas, além dos nitritos, também foram associados ao maior risco de cânceres do trato gastrintestinal. Por exemplo, preparar as carnes com temperaturas elevadas, produzindo um suco

OLIVEIRA, Victor Alves de; OLIVEIRA, Thayse Wilma Nogueira de; ALENCAR, Marcus Vinicius Oliveira Barros de; PERON, Ana Paula; SOUSA, João Marcelo de Castro e. Relação entre consumo alimentar da população nordestina e o alto índice de câncer gástrico nesta região. RevInter Revista Intertox de Toxicologia, Risco Ambiental e Sociedade, v. 7, n. 3 , p. 06-24, out. 2014. 


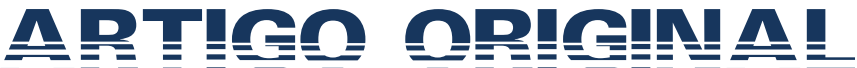

queimado, ou expor a carne diretamente ao fogo, como durante o preparo do churrasco, tem sido desaconselhado pela World Cancer Research Fund, por produzir componentes carcinogênicos na superfície do alimento e aumentar o risco de câncer, principalmente de estômago. A presença de elevada quantidade de benzo [a] pirenos - hidrocarboneto cíclico aromático nos alimentos, considerado um potente carcinogênico - também é correlacionada com essas formas de preparações e parece associar-se com o risco aumentado de câncer do trato gastrintestinal (GARÓFOLO et al. 2004).

\section{Refrigerantes}

Estudos toxicológicos na literatura com corantes alimentares presentes em refrigerantes mostram que alguns desses corantes possuem atividades citotóxicas e mutagênicas. Alves e colaboradores (2009) comprovaram que o corante caramelo, presente nos refrigerantes sabor Cola, apresentou atividade mutagênica em Salmonella typhimurium cepa TA 100. O corante também causou convulsões quando administrado em ratos, camundongos e pintos, afetou adversamente os níveis de glóbulos brancos e linfócitos em animais de laboratório, e inibiu a absorção de vitamina B6 em coelhos, devido à presença de uma impureza chamada de 4-Metilimidazol no corante caramelo, produzida por processos que utilizam amônia. O 4Metilimidazol apresentou potencial carcinogênico em camundongos tratados por 2 anos com concentrações bem elevadas dessa substância. Outros corantes como o amaranto, corante presente em alimentos como, refrigerante sabor Uva, também apresentou potencial mutagênico e carcinogênico quando administrados em camundongos (ALVES et al. 2009).

Gomes e colaboradores (2013) demostraram que os corantes alimentares amarelo crepúsculo, vermelho bordeaux e amarelo tartrazina tem capacidade citotóxica sobre o ciclo celular de Allium cepa L. Cada corante foi avaliado nas doses de 0,4 e 4,0 mL, nos tempos de exposição de 24 e 48 horas, em células de pontas de raízes de Allium cepa L, e os 


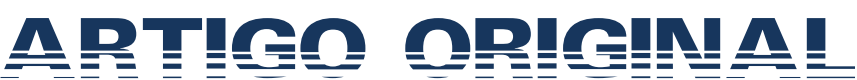

resultados obtidos mostraram que os três corantes, nas doses e tempos de exposição avaliados, foram citotóxicos às células do sistema-teste utilizado.

\section{Salgados, biscoitos e industrializados}

O consumo de alimentos processados e industrializados se mostra prevalente na população de todo o Brasil. No Nordeste, a prevalência de salgados fritos ou assados não foi tão expressivo, porém os biscoitos e industrializados foram citados entre a maior parte da população de todo o país, estando mais presente entre os adolescentes de renda alta e média (JAROSZ et al. 2012).

Nestes alimentos o potencial carcinogênico esta presente na interação dos aditivos alimentares com o organismo. É pertinente a constante preocupação com as substâncias químicas sintéticas, pois estas podem desencadear o câncer, estando presentes nos alimentos como aditivos ou contaminantes ambientais de uso na agricultura como, por exemplo, os agrotóxicos.

Algumas substâncias adicionadas aos alimentos, como os corantes e os conservantes, acumulam-se no organismo e deve-se tomar um cuidado maior quanto as suas doses de ingestão diária. Mesmo considerando-se uma parcial eliminação dessas substâncias e uma degradação metabólica da mesma, deve-se destacar que não existem informações bem definidas para cada substância quanto à dose diária de ingestão e o risco da carcinogênese. Dependendo da substância, uma pequena dose ingerida diariamente e por tempo prolongado, pode resultar no câncer (CESAR e TOLEDO 2011).

As nitrosaminas e os antioxidantes BHA (antioxidante butil hidroxianisol) podem provocar danos e mutações no DNA, provavelmente desencadeando, desta forma, a neoplasia. Também alguns corantes artificiais, nomeadamente a eritrosina e a tartrazina, apresentam este potencial. Essas substâncias alteram o "turn-over" das células durante o seu

OLIVEIRA, Victor Alves de; OLIVEIRA, Thayse Wilma Nogueira de; ALENCAR, Marcus Vinicius Oliveira Barros de; PERON, Ana Paula; SOUSA, João Marcelo de Castro e. Relação entre consumo alimentar da população nordestina e o alto índice de câncer gástrico nesta região. RevInter Revista Intertox de Toxicologia, Risco Ambiental e Sociedade, v. 7, n. 3, p. 06-24, out. 2014. 


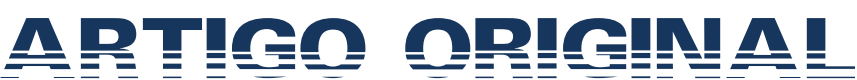

crescimento normal ou no processo de hiperplasia regenerativa e, deste modo, contribuem para a incidência de câncer (ALVES et al., 2009).

A identificação de agentes antimutagênicos e/ou anticarcinogênicos em alimentos é de grande relevância na busca de estratégias para a prevenção do câncer. Atualmente, os corantes mais investigados são os do grupo Azo (amarelo tartrazina, amarelo crepúsculo e vermelho 40), devido aos seus possíveis efeitos mutagênicos e carcinogênicos.

\section{Farinha}

No nordeste, uma característica marcante da alimentação desta região é o alto consumo de farinha de mandioca. A relação entre o consumo de farinha e o câncer, é a alta ingestão de anilina, presente em vários tipos de farinha de mandioca e fonte de radicais aminas e dióxido de nitrogênio. Estes compostos podem atuar como substrato para a formação endógena de nitrosaminas, importantes carcinógenos associados à patogênese do câncer gástrico, particularmente na situação de carência relativa de antioxidantes, em função de um consumo reduzido de legumes e vegetais, embora maior de frutas. Os compostos nitrosos e o nitrato induzem à formação tumoral por meio da sua transformação em nitrito, levando ao aumento na produção de radicais livres (CESAR e TOLEDO 2011).

\section{Alimentação como fator preventivo de câncer gástrico na região Nordeste}

Uma nutrição adequada e apropriada é indispensável para a manutenção da saúde. Contribui tanto para a diminuição de riscos de doenças como também para a restauração da homeostasia em casos de enfermidades. Por meio da alimentação é possível promover a recuperação, reabilitação, desintoxicação e reparo de células, proporcionando maior vitalidade a órgãos e tecidos.

OLIVEIRA, Victor Alves de; OLIVEIRA, Thayse Wilma Nogueira de; ALENCAR, Marcus Vinicius Oliveira Barros de; PERON, Ana Paula; SOUSA, João Marcelo de Castro e. Relação entre consumo alimentar da população nordestina e o alto índice de câncer gástrico nesta região. RevInter Revista Intertox de Toxicologia, Risco Ambiental e Sociedade, v. 7, n. 3, p. 06-24, out. 2014. 


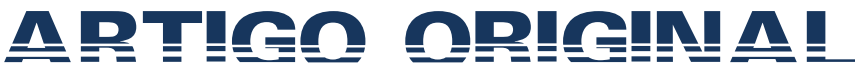

A alimentação pode modificar o processo de carcinogênese, principalmente nos estágios iniciais, proporcionando melhores resultados no tratamento e diagnóstico clínico. Dessa forma, através de um padrão nutricional normal ou equilibrado pode-se reduzir o risco de câncer (ANTUNES et al. 2010).

Foram identificadas várias etapas na patogênese do câncer nas quais os fatores dietéticos podem, supostamente, atuar no aumento ou na diminuição da probabilidade de desenvolvimento de um câncer clínico. Sendo assim é de fundamental importância conhecer as substâncias mutagênicas em cada alimento que pode causar câncer, além de conhecer também alimentos que promovam o processo inverso, identificando sua ação e como este previne tal patologia (FIGUEREDO e SILVA 2003; GARÓFOLO et al. 2004; EPPLEIN et al. 2010).

\section{Frutas e sucos}

O consumo de frutas pela população nordestina não é tão frequente. A fruta mais consumida é a banana, que esteve prevalente não só nesta região mais em todo o Brasil. Outra fruta também citada no consumo, principalmente da população idosa, foi a laranja, que tem boas concentrações de vitamina C. Os sucos também tiveram lugar de destaque no consumo da população nordestina e ocuparam a sexta posição no ranking dos alimentos mais consumidos. Os sucos e frutas estão ligados com a prevenção do câncer, pois as vitaminas possuem propriedades quimiopreventivas que funcionam como antioxidantes em sistemas biológicos (JAROSZ et al. 2012; CESAR e TOLEDO 2011; SHILLS et al. 2009).

As vitaminas mais investigadas com propriedades quimiopreventivas são os carotenóides e as vitaminas $\mathrm{C}$ e $\mathrm{E}$, que funcionam como antioxidantes. O processo carcinogênico é caracterizado por um estado oxidativo crônico, especialmente na etapa de promoção. Além disso, a fase de

OLIVEIRA, Victor Alves de; OLIVEIRA, Thayse Wilma Nogueira de; ALENCAR, Marcus Vinicius Oliveira Barros de; PERON, Ana Paula; SOUSA, João Marcelo de Castro e. Relação entre consumo alimentar da população nordestina e o alto índice de câncer gástrico nesta região. RevInter Revista Intertox de Toxicologia, Risco Ambiental e Sociedade, v. 7, n. 3, p. 06-24, out. 2014. 


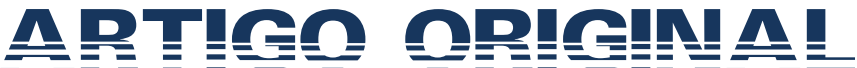

iniciação está associada com dano irreversível no material genético da célula, devido ao ataque de radicais livres. Desse modo, os nutrientes antioxidantes poderiam reduzir o risco de câncer inibindo os danos ao DNA (CESAR e TOLEDO 2011).

Estudos sobre o mecanismo de ação dos carotenóides, na inibição da carcinogênese, revelaram a existência de ações múltiplas: proteção ao DNA contra a mutagênese e genotoxicidade; inibição da proliferação celular; facilitação da comunicação intercelular e estímulo ao sistema imunológico.

As vitaminas $\mathrm{C}$ e $\mathrm{E}$ são importantes antioxidantes, que reduzem a velocidade de iniciação ou previnem a propagação de radicais livres. A vitamina $\mathrm{E}$ é especialmente importante na prevenção da peroxidação de lipídios, enquanto que a vitamina $\mathrm{C}$ reage efetivamente com superóxido e radicais hidroxilas. Esta vitamina desempenha ainda papel importante na redução de radicais cromanoxil e na regeneração da vitamina E. Um mecanismo importante na prevenção do câncer pelo ácido ascórbico é a sua capacidade de inibir a formação de compostos $\mathrm{N}$-nitrosos (N-nitrosaminas). Essa propriedade é de grande significado na redução do risco de câncer em humanos. Sob certas condições, suplementação com ácido ascórbico pode reverter células transformadas em células morfologicamente normais, podendo ser este mais um mecanismo de sua atuação na prevenção de tumores (CESAR e TOLEDO 2011).

Quanto à vitamina $\mathrm{E}$ ( $\alpha$-tocoferol), esta é reconhecida, como a melhor bloqueadora de radicais livres em membranas. Tem sido demonstrado que a vitamina $\mathrm{E}$ inibe reações de nitrosação na célula, sugerindo que possa exercer um efeito anticarcinogênico. A suplementação com vitamina E não altera a progressão de tumores já instalados. Sugere-se que sua ação antitumoral esteja ligada à sua capacidade de inibir a formação de radicais livres, que poderiam danificar o DNA. Da mesma forma que a vitamina C, a vitamina E pode atuar sobre o sistema imunológico aumentando a resposta imune (PACHECO e SGARBIERI 2010).

OLIVEIRA, Victor Alves de; OLIVEIRA, Thayse Wilma Nogueira de; ALENCAR, Marcus Vinicius Oliveira Barros de; PERON, Ana Paula; SOUSA, João Marcelo de Castro e. Relação entre consumo alimentar da população nordestina e o alto índice de câncer gástrico nesta região. RevInter Revista Intertox de Toxicologia, Risco Ambiental e Sociedade, v. 7, n. 3 , p. 06-24, out. 2014. 


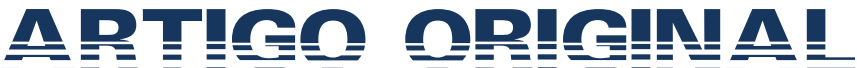

Os estudos de Epplein e colaboradores (2010) notaram que os homens com o mais alto consumo de frutas tinham uma redução de aproximadamente $50 \%$ no risco de câncer gástrico distal em comparação com os homens com o mais baixo consumo de frutas. Esta associação foi especialmente forte entre os fumantes sempre masculinos, para quem aqueles com mais alto nível de ingestão de frutas tiveram quase $60 \%$ menos risco de câncer gástrico distal.

Cavalcante e colaboradores (2011) observaram em seu estudo com camundongos que o caju (Anacardium occidentale) mais precisamente em forma de suco e cajuína (suco processado), as formas mais comumente consumidas no nordeste do Brasil, tem elevado potencial antigenotóxico e anticlastrogênico in vivo, o que pode estar relacionado com os compostos antioxidantes encontrados em ambas as bebidas. Mostrando assim, a capacidade dessa fruta em reduzir os radicais livres que são elementos que reagem com a estrutura do DNA causando modificações nessa estrutura.

\section{Leite e fibras alimentares}

A alimentação da população nordestina apresentou características peculiares quanto ao consumo de leite e fibras alimentares presentes nas saladas cruas. O leite é a forma mais acessível da suplementação alimentar de cálcio e, as fibras solúveis e insolúveis nos legumes e vegetais são responsáveis por uma grande proteção em outros tipos de câncer do trato gastrointestinal.

Cabral e Gruezo (2010) citam alguns estudos de coorte e caso-controle que comprovam que há uma associação entre a ingestão de cálcio e a diminuição dos riscos de câncer colorretal, citam também estudos que mostram que uma ingestão $>250 \mathrm{~g} /$ dia de leite esta relacionada com um menor risco de câncer colorretal quando comparado com uma ingestão $<70 \mathrm{~g} / \mathrm{dia}$, e que o consumo de 500g/dia (aproximadamente 2 copos de leite) estava associado com a redução em $12 \%$ do risco de câncer colorretal.

OLIVEIRA, Victor Alves de; OLIVEIRA, Thayse Wilma Nogueira de; ALENCAR, Marcus Vinicius Oliveira Barros de; PERON, Ana Paula; SOUSA, João Marcelo de Castro e. Relação entre consumo alimentar da população nordestina e o alto índice de câncer gástrico nesta região. RevInter Revista Intertox de Toxicologia, Risco Ambiental e Sociedade, v. 7, n. 3, p. 06-24, out. 2014. 


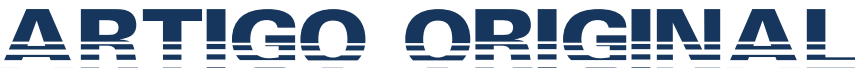

As fibras alimentares também denominadas dietéticas constituem um grupo de componentes funcionais dos mais importantes. É fornecida principalmente pelos alimentos de origem vegetal e tem ações protetoras contra o câncer colorretal (ANTUNES et al. 2010).

Várias hipóteses procuram explicar a ação preventiva da fibra alimentar no câncer de cólon: 1) redução da exposição a agentes carcinogênicos pelo aumento do bolo fecal e/ou diminuição do tempo de trânsito do bolo intestinal; 2) redução da produção de ácidos biliares secundários (desoxicólico e litocólico) pela diminuição de bactérias produtoras de enzimas (7- $\alpha$-desidroxilases) responsáveis pela conversão dos ácidos biliares primários (cólico e quenodesoxicólico) nos ácidos secundários que são pro-carcinogênicos; 3) efeito ligante da fibra a hormônios (estrógenos) promotores de câncer de cólon e mama; 4) produção de ácidos graxos de cadeias curtas que contribuem para a redução do $\mathrm{pH}$ do bolo intestinal e desempenham papel fisiológico importante em nível de tecido epitelial (ANTUNES et al., 2010).

\section{CONSIDERAÇÕES FINAIS}

Tendo em vista todos os dados avaliados, pode-se notar que a alimentação na região Nordeste possui uma estreita relação com o desenvolvimento de vários tipos de câncer, principalmente o de estômago por este órgão ser o primeiro do trato gastrointestinal a ter contato com substâncias carcinogênicas e por ser onde as primeiras interações de grande importância estão acontecendo, aumentando assim sua exposição a substâncias precursoras de dano e que pode induzir ao câncer.

Outro fator importante observado na alimentação dessa região foi a taxa do consumo de alimentos que tem potencial carcinogênico, como carnes, refrigerantes, café, farinha e industrializados, que se apresentou bem mais elevada que o consumo de alimentos como sucos e frutas que previnem o aparecimento de neoplasias gástricas.

OLIVEIRA, Victor Alves de; OLIVEIRA, Thayse Wilma Nogueira de; ALENCAR, Marcus Vinicius Oliveira Barros de; PERON, Ana Paula; SOUSA, João Marcelo de Castro e. Relação entre consumo alimentar da população nordestina e o alto índice de câncer gástrico nesta região. RevInter Revista Intertox de Toxicologia, Risco Ambiental e Sociedade, v. 7, n. 3 , p. 06-24, out. 2014. 


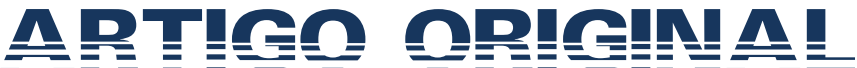

Além disso, deve se levar em consideração o fator econômico que está ligado ao consumo alimentar da população e a disponibilidade de alimentos na região.

Assim, o declínio da incidência do câncer gástrico na região Nordeste, pode se dar com a implementação de uma alimentação rica em frutas e vegetais, visto que o consumo destes alimentos pela população da região é deficiente. É necessário também que aconteça uma reeducação alimentar quanto ao consumo de alimentos com potencial carcinogênico, para que aja um equilíbrio favorável à prevenção desta neoplasia.

\section{REFERÊNCIAS BIBLIOGRÁFICAS}

ALVES RC, CASAL S, OLIVEIRA B. Benefícios do café na saúde: mito ou realidade? Quim. Nova, Vol. 32, No. 8, 2169-2180, 2009.

ANTUNES DC, SILVA IML, CRUZ WMS. Quimioprevenção do Câncer Gástrico. Revista Brasileira de Cancerologia 2010; 56(3):367-374.

CABRAL CM, GRUEZO ND. Ingestão de Cálcio e Vitamina D e Risco de Câncer Colorretal: uma Revisão Bibliográfica. Revista Brasileira de Cancerologia 2010; 56(2): 259-266.

CARVALHO JB, SALGADO NA, SILVA ACM, RAMOS EMLS, DEMACHKI S, ARAÚJO MS. Fatores de risco socioambientais e nutricionais envolvidos na carcinogênese gástrica. Rev. para. Med.; 2011, 25(2/3) abr.-set.

CAVALCANTE AACM, DANTAS SMMM, LEITE AS, MATOS LA, SOUSA JMC, PICADA JN, SILVA J. In vivo Antigenotoxic and Anticlastogenic Effects of Fresh and Processed Cashew (Anacardium occidentale) Apple Juices. J Med Food 14. 2011, 792-798

CESAR ACG, TOLEDO MCB. Comparação do desenvolvimento sócioeconômico com a morbidade hospitalar nos casos de câncer de pulmão, estômago e colorretal entre as regiões Nordeste e Sudeste do Brasil. RevBio - Revista de Biociêcias da Universidade de Taubaté. Vol.17 - $\mathrm{n}^{0} 2$ 2011.

OLIVEIRA, Victor Alves de; OLIVEIRA, Thayse Wilma Nogueira de; ALENCAR, Marcus Vinicius Oliveira Barros de; PERON, Ana Paula; SOUSA, João Marcelo de Castro e. Relação entre consumo alimentar da população nordestina e o alto índice de câncer gástrico nesta região. RevInter Revista Intertox de Toxicologia, Risco Ambiental e Sociedade, v. 7, n. 3, p. 06-24, out. 2014. 


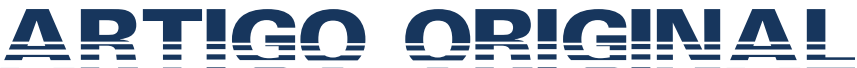

DÜSMAN E, BERTI AP, SOARES LC, VICENTINI VEP. Principais agentes mutagênicos e carcinogênicos de exposição humana. SaBios: Rev. Saúde e Biol., v.7, n.2, mai./ago., 2012. 66-81.

EPPLEIN M, SHU XO, XIANG YB, CHOW WH, YANG G, LI HL, ET AL. Fruit and Vegetable Consumption and Risk of Distal Gastric Cancer in the Shanghai Women's and Men's Health Studies. Am J Epidemiol 2010; 172:397-406.

FIGUEREDO VA, SILVA CHC. A influência da alimentação como agente precursor, preventivo e redutor do câncer. Universitas Ciências da Saúde- vol.01 n.02:317-325.

GOMES KMS, OLIVEIRA MVGA, CARVALHO FRS, MENEZES CC, PERON AP. Citotoxicity of food dyes Sunset Yellow (E-110), Bordeaux Red (E-123), and Tatrazine Yellow (E-102) on Allium cepa L. root meristematic cells. Food Sci. Technol, Campinas, 33(1): 218-223, 2013.

GARÓFOLO A, AVESANI CA, CAMARGO KG, BARROS ME, SILVA SR, TADDEI JAAC, SIGULEM DM. Dieta E Câncer: Um Enfoque Epidemiológico. Rev. Nutr., Campinas, 17(4):491-505, 2004.

Instituto Nacional de Câncer José Alencar Gomes da Silva (INCA). Estimativa 2012: incidência de câncer no Brasil, Rio de Janeiro: Inca, 2012.

Instituto Nacional de Câncer José Alencar Gomes da Silva (INCA). Incidência de câncer no Brasil, Rio de Janeiro: Inca, 2012.

JAROSZ M, SEKUŁA W, RYCHLIK E, FIGURSKA K. Impact of diet on long-term decline in gastric cancer incidence in Poland. World $\mathbf{J}$ Gastroenterol. January 7; 17(1): 89-97. 2011.

MAGALHÃES LP, OSHIMA CTF, SOUZA LG, LIMA JM, CARVALHO L, FORONES NM. Variação de peso, grau de escolaridade, saneamento básico, etilismo, tabagismo e hábito alimentar pregresso em pacientes com câncer de estômago. Arq Gastroenterol. 45. (02). 2008.

MELO MM, NUNES LC, LEITE ICG. Relationship between Dietary Factors and Anthropometric and Gastrointestinal Tract Neoplasms: Investigations Done in Brazil. Revista Brasileira de Cancerologia. 2012. 58(1): 85-95.

PACHECO MTB, SGARBIERI VC. Alimentos Funcionais. Campinas - SP; 2010.

OLIVEIRA, Victor Alves de; OLIVEIRA, Thayse Wilma Nogueira de; ALENCAR, Marcus Vinicius Oliveira Barros de; PERON, Ana Paula; SOUSA, João Marcelo de Castro e. Relação entre consumo alimentar da população nordestina e o alto índice de câncer gástrico nesta região. RevInter Revista Intertox de Toxicologia, Risco Ambiental e Sociedade, v. 7, n. 3 , p. 06-24, out. 2014. 


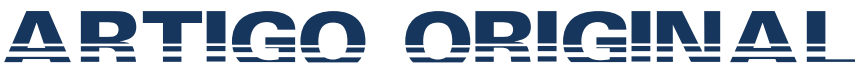

RIBEIRO HF, ALCÂNTARA DFA, MATOS LA, SOUSA JMC, LEAL MF, SMITH MAC, BURBANO RR, BAHIA MO. Cytogenetic characterization and evaluation of c-MYC gene amplification in PG100, a new Brazilian gastric cancer cell line. Braz. Journal Med Biol Res, August 2010, Volume 43(8) 717-721

SHENG GE, FENG X, SHEN L, WEI Z, ZHU Q, SUN J. Association between Habitual Dietary Salt Intake and Risk of Gastric Cancer: A Systematic Review of Observational Studies. Gastroenterology Research and Practice. Gastroenterology Research and Practice: 2012, Vol. 2012, $11 \mathrm{p}$.

SHILLS ME, et al. Nutrição moderna na saúde e na doença, $2^{\mathrm{a}}$ ed. Barueri, SP: Manole; 2009. 781-97.

SOUZA AM, PEREIRA RA, YOKOO EM, LEVY RB, SICHIERI R. Alimentos mais consumidos no Brasil: Inquérito Nacional de Alimentação 2008-2009. Rev Saúde Pública 2013; 47(1 Supl):190S-9S.

OLIVEIRA, Victor Alves de; OLIVEIRA, Thayse Wilma Nogueira de; ALENCAR, Marcus Vinicius Oliveira Barros de; PERON, Ana Paula; SOUSA, João Marcelo de Castro e. Relação entre consumo alimentar da população nordestina e o alto índice de câncer gástrico nesta região. RevInter Revista Intertox de Toxicologia, Risco Ambiental e Sociedade, v. 7, n. 3 , p. 06-24, out. 2014. 